\title{
Oxidative Rearrangement of Flavanones with Thallium(III) Nitrate, Lead Tetraacetate and Hypervalent Iodines in Trimethyl Orthoformate and Perchloric or Sulfuric Acid
}

\author{
István Németh $^{\mathrm{a}}$, Attila Kiss-Szikszai ${ }^{\mathrm{a}}$, Tünde Zita Illyés ${ }^{\mathrm{a}}$, Attila Mándi ${ }^{\mathrm{a}}$, \\ István Komáromi ${ }^{\mathrm{b}}$, Tibor Kurtán ${ }^{\mathrm{a}}$, and Sándor Antus ${ }^{\mathrm{a}}$ \\ a Department of Organic Chemistry, University of Debrecen, H-4032 Debrecen, Hungary \\ b Vascular Biology, Thrombosis and Hemostasis Research Group, Hungarian Academy of \\ Sciences, University of Debrecen, H-4032 Debrecen, Hungary
}

Reprint requests to Prof. Dr. Sándor Antus. Fax: +36-52-512-744.

E-mail: antus.sandor@science.unideb.hu

Z. Naturforsch. 2012, 67b, 1289 - 1296 / DOI: 10.5560/ZNB.2012-0214

Received August 2, 2012

In memory of Professor Ándrás Lipták

An HPLC monitoring protocol has been developed to follow the reaction of flavanone $[( \pm)-1]$ with thallium(III) nitrate, lead tetracetate, phenyliodonium diacetate (PIDA) or [hydroxyl(tosyloxy)iodo]benzene in trimethyl orthoformate. Besides the major ring-contraction product, the 2,3-dihydrobenzo[b]furan derivative $( \pm)-\mathbf{4 a}$, minor components were also identified, and their structures including the relative stereochemistry and a plausible mechanism of formation are reported and compared with literature data. The oxidation reactions were monitored by HPLC at different conditions, and the structure and the ratio of the products were determined and compared. The preferred formation of flavone (5) from ( \pm )-flavanone (1) by PIDA is explained by quantum-chemical calculations on the intermediate formed by the addition of this reagent to the enol ether derivative of $( \pm)-\mathbf{1}$.

Key words: Flavanones, Ring-contraction, Thallium(III) Nitrate, Lead Tetraacetate, Hypervalent Iodine

\section{Introduction}

The oxidative rearrangement of flavanone derivatives induced by thallium(III) nitrate $\left(\mathrm{TTN} \cdot 3 \mathrm{H}_{2} \mathrm{O}\right)$, lead tetraacetate (LTA) or phenyliodonium diacetate (PIDA) is considered a possible route for the preparation of 2,3-dihydro-2-arylbenzo[b]furans. In 1993, Kapoor et al. reported [1] that the oxidative rearrangement of racemic flavanone $[( \pm)-\mathbf{1}]$ by $\mathrm{TTN} \cdot 3 \mathrm{H}_{2} \mathrm{O}$ in trimethyl orthoformate (TMOF) in the presence of a catalytic amount of $70 \%$ perchloric acid resulted in racemic methyl 2,3-dihydro-2-phenylbenzo[b]furan3 -carboxylate $[( \pm)-\mathbf{4 a}$ or $( \pm)-\mathbf{4 b}]$ in good yield (75\%), but the relative configuration at the 2,3dihydrobenzo $[b]$ furan ring was not reported. It is further noteworthy that flavone (5) could be also isolated as a by-product in low yield (15\%) (Scheme 1).

One year later, the transformation of $( \pm)-\mathbf{1}$ to $( \pm)$ 4b with LTA in TMOF in the presence of a catalytic amount of sulfuric acid affording a higher yield (85\%) was published by Khanne [2]. The cis stereochemistry of the product was determined by the ${ }^{1} \mathrm{HNMR}$ data of the carboxylic acid derivative $( \pm)-\mathbf{4 c}[\delta=6.05 \mathrm{ppm}, \mathrm{d}$, $1 \mathrm{H}, 2-\mathrm{H}, J=8.5 \mathrm{~Hz})]$ obtained by the alkaline hydrolysis of $( \pm)-\mathbf{4 b}$.

Moreover, a plausible mechanism of this transformation was also proposed (Scheme 1), the key intermediate of which was supposed to be 3a possessing a lead(IV) atom at $\mathrm{C}-3$ formed from racemic flavanone $[( \pm)-1]$ via enol ether 2 . The subsequent $\mathrm{C}-4 \rightarrow \mathrm{C}-3$ migration of the aryl group followed by a concomitant cleavage of the weak $\mathrm{C}-\mathrm{Pb}$ bond resulted in the cis-2,3dihydrobenzo $[b]$ furan derivative $\mathbf{4 b}$. According to the observation of Kapoor et al., this type of intermediate $\left[3 \mathbf{b} ; \mathrm{X}=\mathrm{Tl}\left(\mathrm{ONO}_{2}\right)_{2}\right]$ also explains the formation of the flavone by-product 5 in the above transformation $[( \pm)$ $\mathbf{1} \rightarrow( \pm)-\mathbf{4 a}+\mathbf{5}]$ by the loss of $2-\mathrm{H}$ followed by the reductive cleavage of the weak carbon-thallium bond. 
<smiles>O=C1C[C@@H](P)Oc2ccccc21</smiles><smiles>COC1=C[C@H](c2ccccc2)[C@H](C)Oc2ccccc21</smiles>

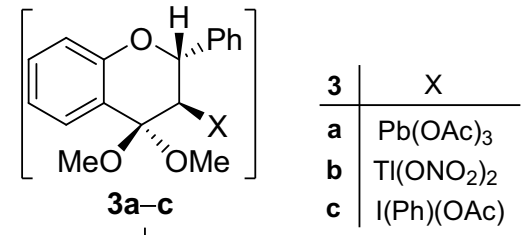<smiles></smiles>

$4 a-c$

\begin{tabular}{c|cc}
$\mathbf{4}$ & $\mathrm{R}$ & $3 \mathrm{H}$ \\
\hline $\mathbf{a}$ & $\mathrm{Me}$ & $\alpha$ \\
$\mathbf{b}$ & $\mathrm{Me}$ & $\beta$ \\
c & $\mathrm{H}$ & $\beta$
\end{tabular}<smiles>O=c1cc(-c2ccccc2)oc2ccccc12</smiles><smiles>[R][C@@H]1C(=O)c2ccccc2O[C@H]1c1ccccc1</smiles>

$6 a, b$ \begin{tabular}{c|c} 
& $\mathrm{R}$ \\
\hline $\mathbf{a}$ & $\mathrm{Me}$ \\
$\mathbf{b}$ & $\mathrm{H}$
\end{tabular}<smiles>O=c1c(-c2ccccc2)coc2ccccc12</smiles>

Scheme 1. (i) TMOF, $70 \% \mathrm{HClO}_{4}$ or conc. $\mathrm{H}_{2} \mathrm{SO}_{4}$; (ii) TTN $3 \mathrm{H}_{2} \mathrm{O}$ or LTA or PIDA, (iii) $\mathrm{H}_{2} \mathrm{O}, \mathrm{H}^{+}$, r. t.

In 1995, Prakash and Tanwar reported [3] that the ring-contraction of $( \pm)-\mathbf{1}$ with PIDA in TMOF in the presence of a catalytic amount of sulfuric acid at room temperature also resulted in methyl 2,3-dihydro2-phenylbenzo $[b]$ benzofuran-3-carboxylate $[( \pm)-\mathbf{4 a}$ or $( \pm)-4 b]$ together with cis-3-methoxyflavanone [( \pm 6a] and flavone (5) in 50\%, 35\% and $15 \%$ yields, respectively. Interestingly the relative stereochemistry of the major product $[( \pm)-\mathbf{4 a}$ or $( \pm)-\mathbf{4 b}]$ was not determined, although it was suggested that during the formation of the hypervalent iodine intermediate 3c $[\mathrm{X}=\mathrm{I}(\mathrm{Ph})(\mathrm{OAc})]$, the electrophilic addition of PIDA at $\mathrm{C}-3$ of the enol ether of $( \pm)-\mathbf{1}$ took place anti to the $\mathrm{C}-2$ phenyl group. Moreover, they recognized that in the case of flavanones containing a $p$-methoxy substituent at the 2-phenyl ring, the formation of the corresponding isoflavone ( $7, \mathrm{C}-3$ phenyl is replaced by $p$ methoxyphenyl) was also observed together with the corresponding flavone $(\mathbf{5}, \mathrm{C}-2$ phenyl is replaced by $p$ methoxyphenyl).

Recently, on the basis of NMR, ECD and chiral HPLC studies, we have proved that the ringcontraction of $(-)-(2 S)$-flavanone $[(-)-1]$ under the conditions used by Prakash and Tanwar [3] takes place stereoselectively, controlled by the configuration of the C-2 phenyl group to result in $(+)-(2 S, 3 S)-\mathbf{4 a}$, which can be isolated in moderate $(25 \%)$ yield [4]. Moreover, we have found that the synthesis of $(+)-(2 R, 3 R)-9 \mathbf{a}$ could be performed by ring-contraction of $(+)-(2 R)-2^{\prime}-$ benzyloxyflavanone (8a) under the above mentioned conditions in $48 \%$ yield, which allows the construction of the pterocarpan skeleton with cis B/C-ring junction $[(+)-(6 \mathrm{a} S, 11 \mathrm{a} S)-\mathbf{1 0 a}]$ in five steps as shown in Scheme 2 [5].

Although this approach offered a facile enantioselective route to naturally occurring biologically active 


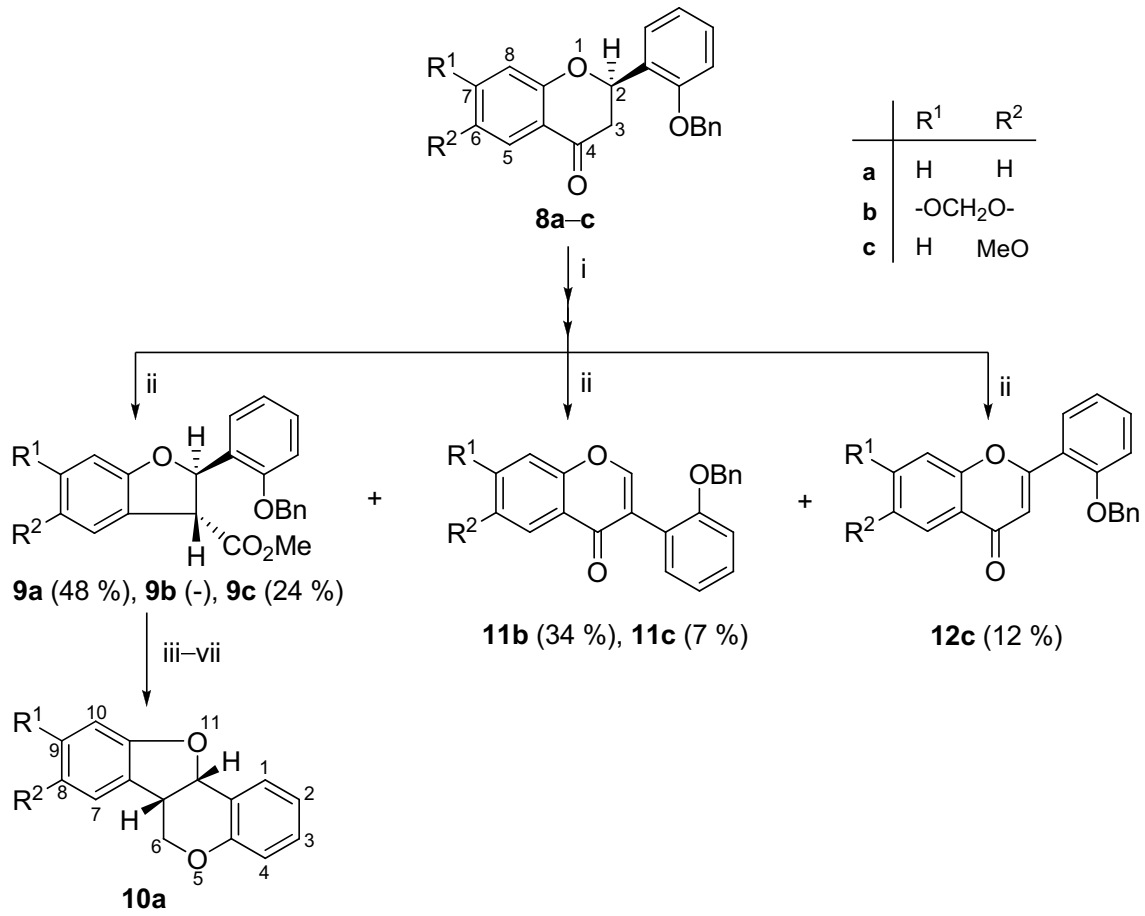

Scheme 2. (i) TTN.3 $\mathrm{H}_{2} \mathrm{O}$, TMOF, $\mathrm{HClO}_{4}$, r.t.; (ii) $\mathrm{H}_{2} \mathrm{O}, \mathrm{H}^{+}$, r. t.; (iii) $\mathrm{LiAlH}_{4}$, $\mathrm{Et}_{2} \mathrm{O}$, r.t.; (iv) TsCl, py., r. t.; (v) $\mathrm{H}_{2} / \mathrm{Pd}$, $\mathrm{MeOH}$; (vi) $\mathrm{NaOMe}, \mathrm{MeOH}$; (vii) PTS, $\mathrm{C}_{6} \mathrm{H}_{6}, \Delta$.

pterocarpans possessing a hydroxy or alkoxy function at C-3, C-8 and C-9 [6, 7], surprisingly the treatment of $2^{\prime}$-benzyloxyflavanone $( \pm)-8 \mathbf{b}$ possessing an electrondonating methylenedioxy group at C-6 and C-7 with TTN $3 \mathrm{H}_{2} \mathrm{O}$ or PIDA did not give the ring-contraction product $[( \pm)-9 \mathbf{b}]$ at all. Instead, $( \pm)-\mathbf{8 b}$ underwent 2aryl migration to give the isoflavone derivative $\mathbf{1 1 b}$ in moderate yield (34\%). The treatment of $[( \pm)-8 \mathbf{c}]$, possessing an electron-donating methoxy group only at $\mathrm{C}$ 6 , with $\mathrm{TTN} \cdot 3 \mathrm{H}_{2} \mathrm{O}$ led to ring-contraction $[( \pm)-8 \mathbf{c} \rightarrow$ $( \pm)-9 c]$ in moderate yield $(24 \%)$ accompanied by $2-$ aryl migration and dehyrogenation as well $[( \pm)-8 \mathbf{c} \rightarrow$ $( \pm)-11 c(7 \%)+12 c(16 \%)]$. In the reaction of $( \pm)-$ 8c with PIDA as electrophilic reagent, only a dehydrogenation resulting in the flavone derivative $12 \mathrm{c}(51 \%)$ could be observed [8].

In order to reveal the principles governing the outcome of the ring-contraction of flavanones mediated by $\mathrm{TTN} \cdot 3 \mathrm{H}_{2} \mathrm{O}$, LTA and hypervalent iodine, HPLC monitoring was carried out on the reaction of $( \pm)-\mathbf{1}$ with $\mathrm{TTN} \cdot 3 \mathrm{H}_{2} \mathrm{O}$, LTA, PIDA, and [hydroxy(tosyloxy)iodo]benzene (HTIB) under different conditions.

\section{Results and Discussion}

The HPLC monitoring of the transformation of racemic flavanone $[( \pm)-\mathbf{1}]$ with $1.1 \mathrm{~mol}$ equivalents of $\mathrm{TTN} \cdot 3 \mathrm{H}_{2} \mathrm{O}$ in TMOF in the presence of a catalytic amount of $70 \%$ perchloric acid at room temperature has clearly indicated that the conversion of $( \pm)-\mathbf{1}$ reached $98 \%$ in 30 minutes to result in a complex mixture of products as shown in Fig. 1.

Many components of this mixture could be nearly base line-separated, and besides racflavanone $[( \pm)-1(2 \%)]$, rac-methyl 2,3-dihydro-2phenylbenzo $[b]$ furan-3-carboxylate $[( \pm)-4 a(76 \%)]$, flavone [5 (3\%)], and isoflavone [7 (9\%)] could be identified unequivocally by comparing with authentic samples (see entry 1 in Table 1). Moreover, the compound with $t_{\mathrm{R}}=8.95 \mathrm{~min}$ could also be isolated by preparative TLC and identified as methyl 2-phenylbenzo[b]furan-3-carboxylate $(\mathbf{1 7})$ by its MS and NMR data, as well as by comparison with an authentic sample obtained by the oxidation of $( \pm)$ $4 a$ with 2,3-dichloro-5,6-dicyano-1,4-benzoquinone 


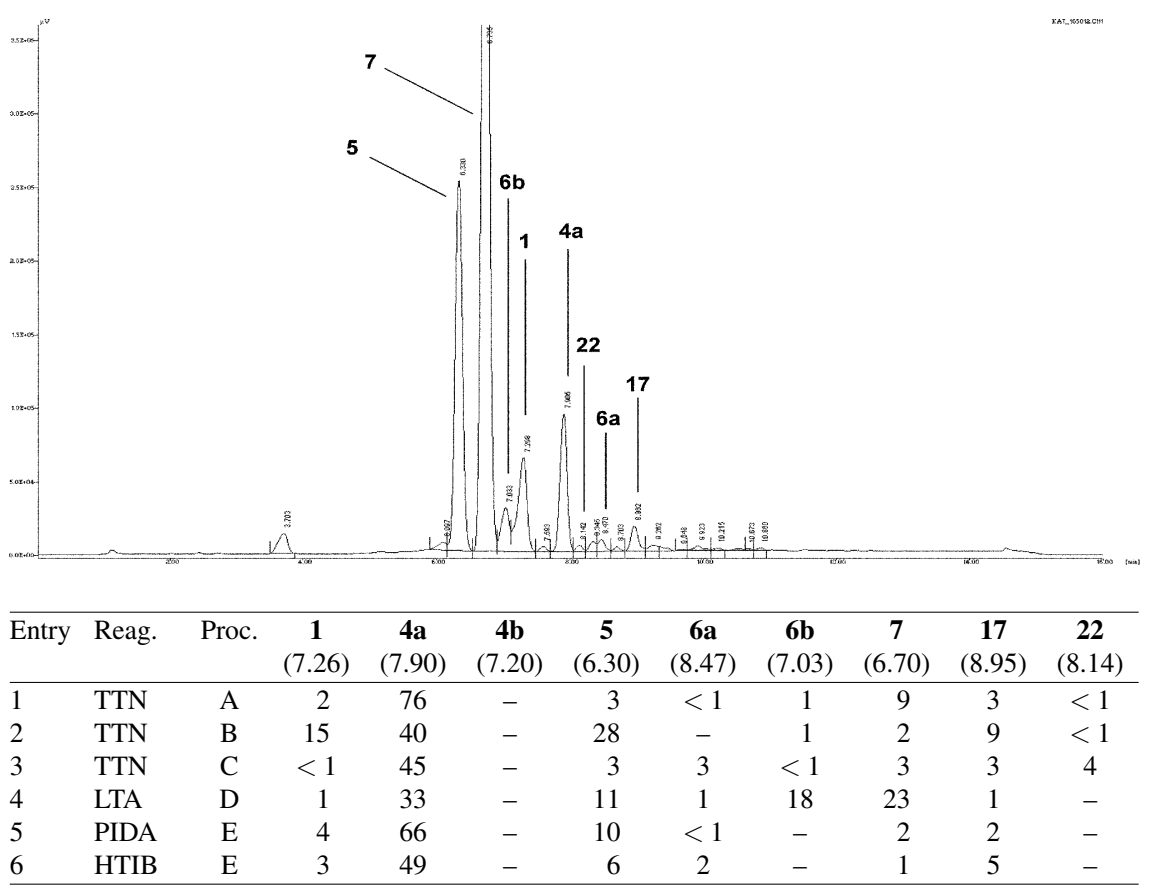

Fig. 1. HPLC pattern of the crude product of the transformation of $( \pm)-\mathbf{1}$ with $\mathrm{TTN} \cdot 3 \mathrm{H}_{2} \mathrm{O}$ at room temperature.

Table 1. Yields and retention times of the compounds of the transformation of $( \pm)-\mathbf{1}$.

Yields (in \%) of compounds with $t_{\mathrm{R}}$ (in min) given in parentheses. Proc. A-E see Exp. Section.

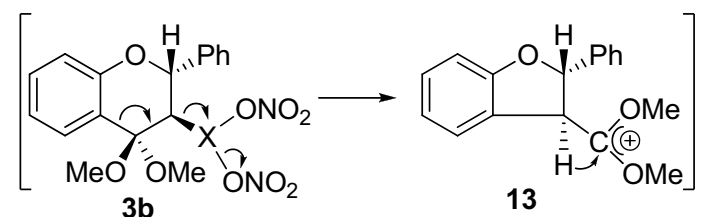


<smiles>CO[C@]1(O)c2ccccc2OC[C@H]1c1ccccc1</smiles>

$3 \mathbf{a}$

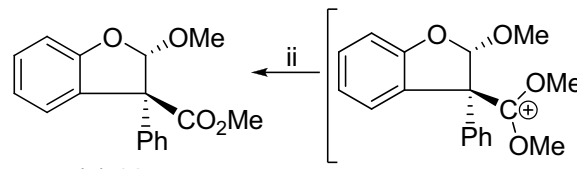

$( \pm)-22$

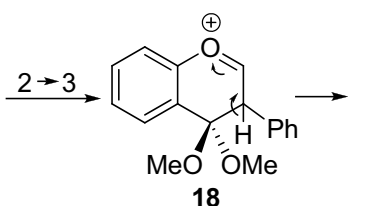

18<smiles>CC=CC[C@]1(OC)C(c2ccccc2)=COc2ccccc21</smiles>

$\downarrow \mathrm{TTN} \cdot 3 \mathrm{H}_{2} \mathrm{O}$

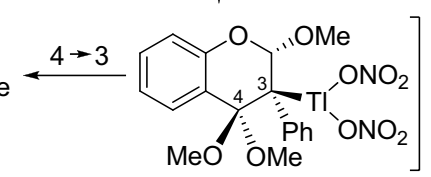

20

Scheme 4. (i) TTN.3 $\mathrm{H}_{2} \mathrm{O}$, TMOF, $70 \% \mathrm{HClO}_{4}$, r. t.; (ii) $\mathrm{H}_{2} \mathrm{O}, \mathrm{H}^{+}$, r. t.

a simple deprotonation resulted in racemic 2-phenyl3-(2', $2^{\prime}$-dimethoxy)methylenebenzo[b]furan $[( \pm)-\mathbf{1 4}]$, which reacted with TTN $3 \mathrm{H}_{2} \mathrm{O}$ under product control [9] to afford the corresponding thallium adduct 15 possessing the bulky phenyl and trimethoxymethyl groups in the thermodynamically preferred anti position. The 2-phenyl-3-trimethoxymethylbenzo[b]furan (16) formed by an oxidative elimination, and subsequent hydrolysis during the workup gave methyl 2phenylbenzo[b]furan-3-carboxylate (17).

If the reaction of $( \pm)-\mathbf{1}$ was carried out at $-10^{\circ} \mathrm{C}$, it took place significantly more slowly as indicated by the $85 \%$ conversion in 30 minutes, and there was a considerable change in the ratio of the products formed under these conditions (see entry 2 in Table 1). According to our expectation the formation of the enol ether 2 took place more slowly, and therefore the direct transformation of racemic flavanone [( \pm -1] by $\mathrm{TTN} \cdot 3 \mathrm{H}_{2} \mathrm{O}$ via its enol form into flavone (5) as described by Varma and Varma [10] took place as well, which significantly increased the yield of 5 (from 3 to $28 \%$ ). Remarkably, the overall yield of flavone (5) $(28 \%)$ and benzo[b]furan $17(9 \%)$ did not significantly deviate from the decrease in yield of the ring contraction product $( \pm)-\mathbf{4 a}(40 \%)$. Moreover, a substantial decrease of the yield of isoflavone (7) could also be observed. The by-product related to $t_{\mathrm{R}}=8.14 \mathrm{~min}$, formed in $0.8 \%$ yield, could be isolated by preparative TLC. Its structure has been established by NMR $\left({ }^{1} \mathrm{H},{ }^{13} \mathrm{C}\right.$, NOESY, COSY, HSQC, HMBC) and MS evidences to be the methyl 2,3-dihydro-2-methoxy-3phenylbenzo[b]furan-3-carboxylate of $\left(2 S^{*}, 3 S^{*}\right)$ configuration $[( \pm)-22]$. On the basis of its structure, it may form from the precursor 19, which can be obtained from $3 \mathbf{a}$ by a $2 \rightarrow 3$ phenyl migration with concomi- tant cleavage of the week carbon-thallium bond followed by a deprotonation $(\mathbf{3 a} \longrightarrow \mathbf{1 8} \longrightarrow \mathbf{1 9})$ as shown in Scheme 4.

Due to the well-known polarity of the enol ether function of 19, the addition of TTN took place at position C-3 leading to 20. In the next step, it underwent a C-4 $\rightarrow$ C-3 aryl group migration with simultaneous reductive cleavage of the $\mathrm{C}-3$ carbon-thallium bond to result in the corresponding 2,3-dihydrobenzo[b]furan derivative 21, which on treatment with water during the workup gave $( \pm)-\left(2 S^{*}, 3 S^{*}\right)-\mathbf{2 2}$. The decrease of the yield of isoflavone (7) has been found indeed commensurable with the yield of $\mathbf{2 2}$ (entry 3 ). The treatment of 7 with TTN $3 \mathrm{H}_{2} \mathrm{O}$ in TMOF in the presence of a catalytic amount of $70 \%$ perchloric acid at room temperature for $30 \mathrm{~min}$ resulted in a mixture of products, from which $\left(2 S^{*}, 3 S^{*}\right)-22$ could be isolated by preparative TLC.

Interestingly, the longer time for the formation of enol ether 2 has also influenced the yield of $( \pm$ )-4a (see entries 1 and 3 in Table 1). According to our expectation the yield of 5 did not change ( $3 \%$ ), but the yield of $( \pm)-\mathbf{4 a}$ increased by $31 \%$. This clearly indicated that a polymerization of enol ether $\mathbf{2}$ took also place due to the presence of $70 \%$ perchloric acid.

Both TLC and HPLC monitoring of the transformation of $( \pm)-\mathbf{1}$ by LTA under the conditions used by Khanne [2] have clearly shown that the conversion of $( \pm)$-1 reached $99 \%$ in 2 hours, and formation of $( \pm)$ 4a $(33 \%), \mathbf{5}(11 \%), \mathbf{6 a}, \mathbf{b}(1 \%, 18 \%), 7(23 \%)$, and 17 ( $1 \%$ ) could be detected (entry 4 in Table 1$)$. In contrast to the observation of Khanne, the formation of $( \pm)-\mathbf{4 b}$ could not be observed at all.

The HPLC monitoring of the transformation of $( \pm)$ $\mathbf{1}$ by PIDA or HTIB in the presence of sulfuric acid 

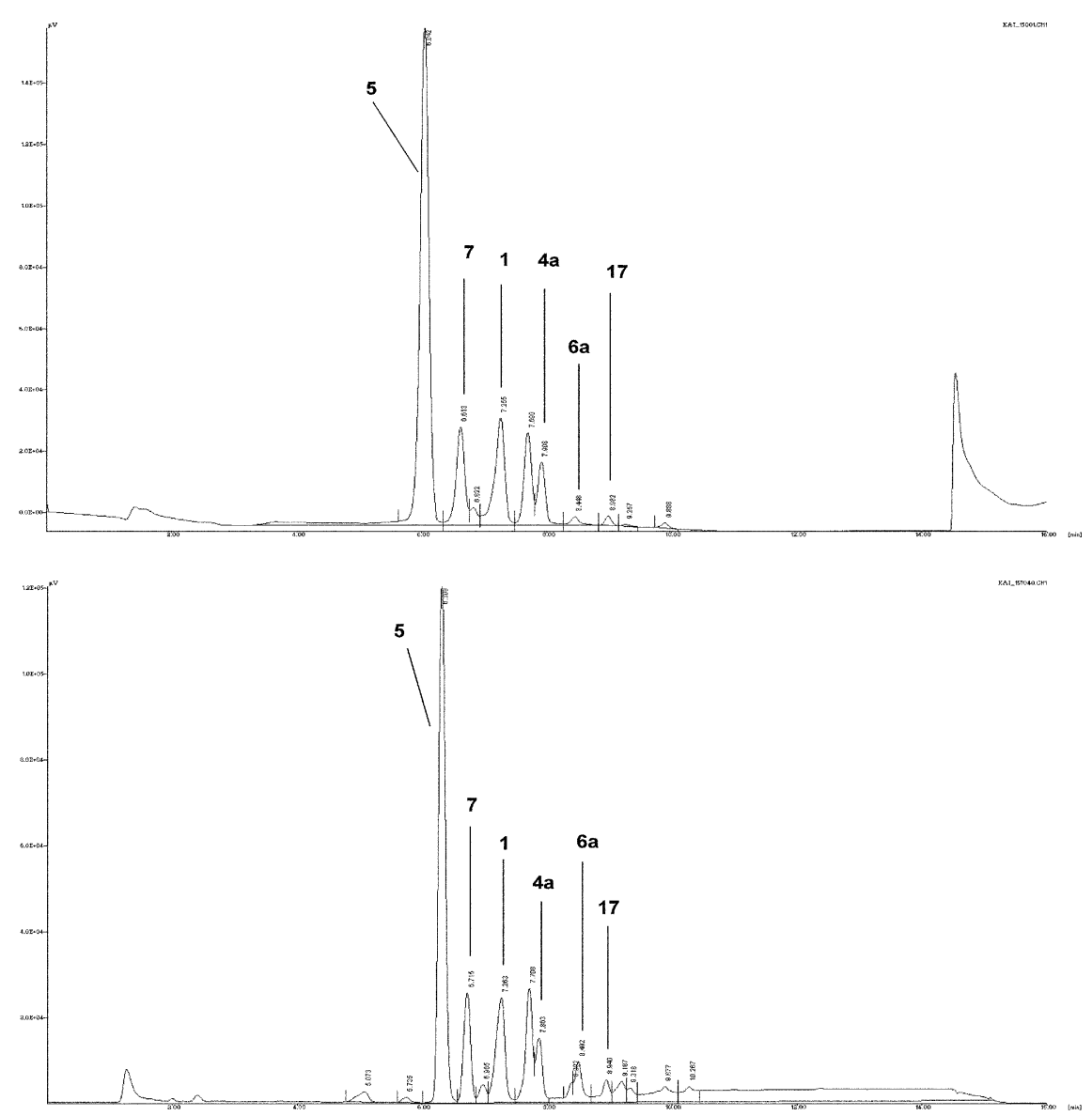

Fig. 2. HPLC pattern of the crude product of the transformation of $( \pm)-\mathbf{1}$ with PIDA at room temperature. in TMOF at room temperature was also carried out. In both cases the transformations took place significantly more slowly than with TTN $\cdot 3 \mathrm{H}_{2} \mathrm{O}$, and their product profiles were similar as shown in Figs. 2 and 3, but significantly different from those obtained by TTN $3 \mathrm{H}_{2} \mathrm{O}$ (see Fig. 1). In good agreement with the observation of Prakash and Tanwar, [3] the ring contraction of $( \pm)-\mathbf{1}$ by PIDA led to $( \pm)-\mathbf{4 a}(66 \%)$ as the main product, and the formation of flavone (5) was also preferred (entry 5 in Table 1).

The preferred formation of flavone (5) with PIDA as oxidizing agent could be readily explained by quantum-chemical calculations. If both $( \pm)-\mathbf{4 a}$ and 5 form via the intermediate $( \pm)-3 \mathbf{c}$ as depicted in Scheme 1, the preferred formation of $\mathbf{3 c}$ may have a decisive role in the outcome of this reaction. Based on the T-shaped geometry of iodine(III) compounds well documented in the literature [11] and the preferred half-chair conformation of the fused $O$-heterocyclic ring, two arrangements of the C-3 phenyl iodonium acetate moiety are feasible for $( \pm)-\mathbf{3 c}$ as shown in Scheme 5.

The computational data obtained by relaxed scans performed along the C-3-I bond clearly showed that the cleavage of the I-OAc bond took place simultaneously with that of the C-3-I bond [12]. Therefore in case of conformer A where the acetoxy group is in proximity of $2-\mathrm{H}$, it could be simply removed by the leaving acetoxy group resulting in $\mathbf{5}$ with a higher yield $(10 \%)$ than in case of TTN $3 \mathrm{H}_{2} \mathrm{O}(3 \%)$. The activation energy of this transformation calculated at the ONIOM(B3LYP/LANL2DZ:AM1) level has been found to be only $\sim 45 \mathrm{~kJ} \mathrm{~mol}^{-1}$ which also indicates that oxidative elimination of $\mathbf{3 c}$ to flavone (5) must be a preferred pathway, which has been observed indeed experimentally. In the other case (conformer B), the carbenium ion $\mathbf{2 3}$ is formed which may be strongly stabilized by a neighboring methoxy group to give the 
(a)
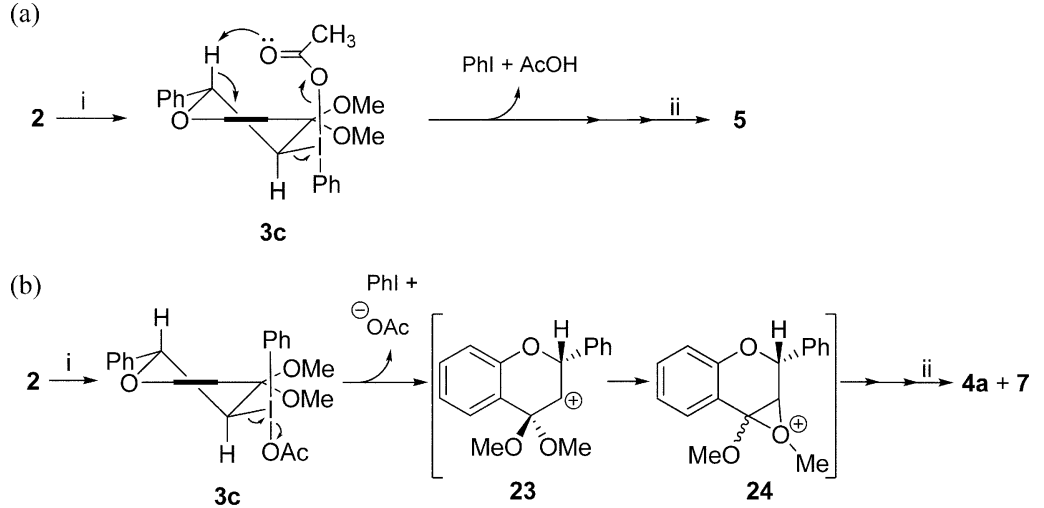

Scheme 5. (i) PIDA, TMOF, $\mathrm{HClO}_{4}$, r. t.; (ii) $\mathrm{H}_{2} \mathrm{O}, \mathrm{H}^{+}$, r. t.

oxenium ion $\mathbf{2 4}$, and its transformation results in the mixture of $( \pm)-\mathbf{4 a}$ and 7 in 66 and $2 \%$ yield, respectively.

\section{Conclusion}

Flavanone $[( \pm)-\mathbf{1}]$, when treated with $\mathrm{TTN} \cdot 3 \mathrm{H}_{2} \mathrm{O}$ in TOMF in the presence of $70 \%$ perchloric acid at room temperature, rearranges to methyl 2,3-dihydro-2phenylbenzo $[b]$ furan-3-carboxylate $[( \pm)-\mathbf{4 a}]$ in $76 \%$ yield, and beside this compound not only flavones (5), as published by Kapoor et al. [1], but also cis-3-methoxyflavanone (6a), cis-3-hydroxyflavanone (6b), isoflavone (7), methyl 2-phenylbenzo[b]furan-3carboxylate (17), and $2 S^{*} 3 S^{*}$-2-methoxy-3-methoxycarbonyl-3-phenyl-2,3-dihydrobenzo[b]furan $[( \pm)-22]$ are formed in $<1,1,9,3$ and $<1 \%$ yield, respectively. In contrast to the observation of Khanna [2], the treatment of $( \pm)-\mathbf{1}$ with LTA in TMOF in the presence of a catalytic amount sulfuric acid did not afford ( \pm )$\mathbf{4 b}$ in $80 \%$ yield as a sole product, but $( \pm)-\mathbf{4 a}, \mathbf{5}, \mathbf{6 a}$, $\mathbf{6 b}, \mathbf{7}$, and $\mathbf{1 7}$ were formed in 33,11, 1, 18, 23 and $1 \%$ yield, respectively. The treatment of $( \pm)-\mathbf{1}$ with PIDA reported by Prakash and Tanwar [3] led in our hands to $( \pm)-4 a(66 \%), 5(10 \%)$, and $( \pm)-6 a(<1 \%)$ in significantly different yields from those reported $(50 \%, 15 \%$, $35 \%$, resp.). Moreover the formation of $7(2 \%)$ and $\mathbf{1 7}$ ( $2 \%$ ) could also be detected. In case of HTIB a similar profile of products has been observed.

\section{Experimental Section}

Analytical RP-HPLC was performed on a Jasco HPLC System; data acquisition was performed using Borvin chro- matography software; UV detector: UV-2075 Plus, Pump PU-2089 Plus. The flow rate was $1 \mathrm{~mL} \mathrm{~min}^{-1}$. An injection volume of $20 \mu \mathrm{L}$ and a column temperature of $25^{\circ} \mathrm{C}$ was used. The $\mathrm{C} 185 \mu \mathrm{m}, 150 \times 4.6 \mathrm{~mm}^{2}$ Gemini chromatographic column (Phenomenex) was used for these studies. A solution of $\mathrm{KI}$ (in $\mathrm{CH}_{3} \mathrm{CN}$ ) was used for dead time $\left(t_{\mathrm{D}}\right)$ determination. Retention times $\left(t_{\mathrm{R}}\right)$ were measured in minutes. A mixture of $\mathrm{CH}_{3} \mathrm{CN}$ (HPLC grade) and $\mathrm{H}_{2} \mathrm{O}$ (HPLC grade) was used as a mobile phase. The gradient program was linear from $50 \%$ to $100 \%$ in 8 min and then held for $4 \mathrm{~min}$. A detection wavelength of $254 \mathrm{~nm}$ was chosen, and the measured peak of the compounds was corrected on the basis of the ppm value obtained from the HPLC chromatogram of the corresponding analytically pure compound.

Analytical and preparative TLC were done on plates Kieselgel $60 \quad \mathrm{~F}_{254}$ (Merck). The reagents thallium(III) nitrate $\left.\left[\mathrm{Tl}\left(\mathrm{NO}_{3}\right)_{3} \cdot 3 \mathrm{H}_{2} \mathrm{O}\right)\right]$, lead tetraacetate $\left(\mathrm{Pb}(\mathrm{OAc})_{4}\right.$, phenyliodonium diacetate $\left[\mathrm{PhI}(\mathrm{OAc})_{4}\right]$ and [hydroxyl(tosyloxy)iodo]benzene $[\mathrm{PhI}(\mathrm{OH}) \mathrm{OTs}]$, as well as the compounds rac-flavanone (1), flavone (5) and isoflavone (7) were purchased from Sigma-Aldrich. Compounds $( \pm)-\mathbf{4 a}$, 4b, 17, [4], ( \pm$)-6 \mathbf{a},[13]$ and $( \pm)-6 \mathbf{b}[14]$ were prepared according to the literature. For workup the solutions were dried $\left(\mathrm{MgSO}_{4}\right)$ and concentrated in vacuo. ${ }^{1} \mathrm{H}$ and ${ }^{13} \mathrm{C} \mathrm{NMR}$ spectra were recorded with a Bruker AM-360 instrument in $\mathrm{CDCl}_{3}$ with TMS as internal standard. The chemical shifts are given on the $\delta$ scale in ppm.

\section{Procedures for the transformations of racemic flavanone [(土)-1]}

Procedure A: After $5 \mathrm{~min}$. $\mathrm{Tl}\left(\mathrm{NO}_{3}\right)_{3} \cdot 3 \mathrm{H}_{2} \mathrm{O}(1.1 \mathrm{mmol})$ was added to a stirred solution of $( \pm)-\mathbf{1}(1 \mathrm{mmol})$ in TMOF $(2 \mathrm{~mL})$ and $70 \%$ aqueous $\mathrm{HClO}_{4}(\mathrm{xx} \mathrm{mL}, 3 \mathrm{mmol})$ at r.t., and the reaction mixture was stirred at r.t. for $30 \mathrm{~min}$. The reaction mixture was diluted with $\mathrm{CH}_{2} \mathrm{Cl}_{2}$ and the $\mathrm{Tl}(\mathrm{I})$ salt 
filtered off. The organic phase was washed with a saturated solution of sodium hydrogen carbonate and water and dried. The evaporation of the solution gave a crude product as an oil. The compounds detected by HPLC are given in entry 1 of Table 1.

Procedure B: After $5 \mathrm{~min} \mathrm{Tl}\left(\mathrm{NO}_{3}\right)_{3} \cdot 3 \mathrm{H}_{2} \mathrm{O}(1.1 \mathrm{mmol})$ was added to a stirred solution of $( \pm)-\mathbf{1}(1 \mathrm{mmol})$ in TMOF $(2 \mathrm{~mL})$ and $70 \% \mathrm{HClO}_{4}(3 \mathrm{mmol})$ at $-10{ }^{\circ} \mathrm{C}$, and the reaction mixture was stirred at $-10{ }^{\circ} \mathrm{C}$ for $30 \mathrm{~min}$. Workup was the same as in Procedure A. The compounds detected by HPLC are given in entry 2 of Table 1 .

Procedure C: After $30 \mathrm{~min} \mathrm{Tl}\left(\mathrm{NO}_{3}\right)_{3} \cdot 3 \mathrm{H}_{2} \mathrm{O}(1.1 \mathrm{mmol})$ was added to a stirred solution of $( \pm)-\mathbf{1}(1 \mathrm{mmol})$ in TMOF $(2 \mathrm{~mL})$ and $70 \% \mathrm{HClO}_{4}(3 \mathrm{mmol})$ at r.t., and the reaction mixture was stirred at r.t. for $30 \mathrm{~min}$. Workup was the same as in Procedure A. The compounds detected by HPLC are given in entry 3 of Table 1 .

Procedure D: After $5 \mathrm{~min} \mathrm{~Pb}(\mathrm{OAc})_{4}(1.1 \mathrm{mmol})$ was added to a stirred solution of $( \pm)-\mathbf{1}(1 \mathrm{mmol})$ in TMOF $(2 \mathrm{~mL})$ and conc. sulfuric acid at r.t., and the reaction mixture was stirred at r.t. for $2 \mathrm{~h}$. Workup was the same as in Procedure A. The compounds detected by HPLC are given in entry 4 of Table 1.

Procedure E: After $5 \mathrm{~min} \mathrm{PhI}(\mathrm{OAc})_{2}$ or $\mathrm{PhI}(\mathrm{OH}) \mathrm{OTs}$ $(1.08 / 1.08 \mathrm{mmol})$ was added to a stirred solution of $( \pm)-1$ $(1 \mathrm{mmol})$ in TMOF $(2 \mathrm{~mL})$ and conc. sulfuric acid $(\mathrm{xx} \mathrm{mL})$ at r.t., and the reaction mixture was stirred at r.t. for $2 \mathrm{~h}$. The reaction mixture was poured into water, and products were extracted with $\mathrm{CH}_{2} \mathrm{Cl}_{2}$, washed with water and dried. After evaporation of the solution the crude product was obtained as an oil. The compounds detected by HPLC are given in entry 5 and 6 of Table 1, respectively.
$2 S^{*}, 3 S^{*}$-Methyl 2,3-dihydro-2-methoxy-3-phenylbenzo-

[b]furan-3-carboxylate (22)

After $5 \mathrm{~min} 490 \mathrm{mg}(1.1 \mathrm{mmol})$ of TTN $\cdot 3 \mathrm{H}_{2} \mathrm{O}$ was added to a stirred solution of $222 \mathrm{mg}$ ( $1 \mathrm{mmol}$ ) isoflavone (7) in trimethyl orthoformate $(2 \mathrm{~mL})$ and $70 \% \mathrm{HClO}_{4}(0.19 \mathrm{~mL})$ at r. t., and the stirring was continued for $30 \mathrm{~min}$ with monitoring of the reaction by TLC (hexane-ethyl acetate, $4: 1$, v/v). The reaction mixture was diluted with $\mathrm{CH}_{2} \mathrm{Cl}_{2}$ and stirred further for $15 \mathrm{~min}$. The thallium salt was removed by filtration and the organic extract washed with a saturated solution of sodium hydrogen carbonate and water. It was dried and the solvent removed under reduced pressure. The compound of $R_{\mathrm{f}}=0.79$ was isolated by column chromatography on silica gel, using hexane-ethyl acetate $(6: 1, \mathrm{v} / \mathrm{v})$ as eluent, and its purification by preparative TLC (hexane-ethyl acetate $(4: 1, \mathrm{v} / \mathrm{v}))$ resulted in 22 as a colorless oil. Yield $58.9 \mathrm{mg}$ $(21 \%) .-{ }^{1} \mathrm{H}$ NMR $\left(360 \mathrm{MHz}, \mathrm{CDCl}_{3}\right): \delta=3.15(3 \mathrm{H}, \mathrm{s}$, $\left.\mathrm{OCH}_{3}\right), 3.28\left(3 \mathrm{H}, \mathrm{s}, \mathrm{COOCH}_{3}\right), 5.12(1 \mathrm{H}, \mathrm{s}, 2-\mathrm{H}), 7.06(\mathrm{~d}$, $1 \mathrm{H}, 4-\mathrm{H}, J_{4.5}=8.2 \mathrm{~Hz}$ ), $7.13(\mathrm{t}, 1 \mathrm{H}, 5-\mathrm{H}), 7.43-7.53$ (overlapping signals, $\left.5 \mathrm{H}, 2^{\prime}, 3^{\prime}, 4^{\prime}, 5^{\prime}, 6^{\prime}-\mathrm{H}\right), 7.58(\mathrm{dd}, 1 \mathrm{H}, 6-\mathrm{H})$, $8.04\left(\mathrm{dd}, 1 \mathrm{H}, 7-\mathrm{H}, J_{6,7}=7.8 \mathrm{~Hz}, J_{5,7}=1.7 \mathrm{~Hz}\right) .-{ }^{13} \mathrm{C} \mathrm{NMR}$ $\left(90 \mathrm{MHz}, \mathrm{CDCl}_{3}\right): \delta=52.9\left(\mathrm{COOCH}_{3}\right), 56.8\left(\mathrm{OCH}_{3}\right), 81.06$ (C-3), 105.9 (C-2), 118.0 (C-4), 120.4 (C-9), 122.0 (C-5), $127.5\left(\mathrm{C}-4^{\prime}\right), 127.6(\mathrm{C}-7), 128.2\left(\mathrm{C}-3^{\prime}, \mathrm{C}-5^{\prime}\right), 129.0\left(\mathrm{C}-2^{\prime}\right.$, C-6' $\left.{ }^{\prime}\right), 133.3\left(\mathrm{C}-1^{\prime}\right), 136.1$ (C-6), $156.4(\mathrm{C}-8), 188.3$ (CO) HRMS: $m / z=285.102[\mathrm{M}+\mathrm{H}]^{+}$.

\section{Acknowledgement}

We are grateful to the National Research Foundations (OTKA K81701 and TAMOP 4.2.2./B-10/1) for the financial support of our research.
[1] M. S. Khanna, O. V. Singh, C. H. P. Garg, R. P. Kapoor, Synth. Commun. 1993, 23, 585-590.

[2] M. S. Khanna, O. P. P. I. Briefs 1994, 26, 125 - 127.

[3] O. Prakash, M. P. Tanwar, Bull. Chem. Soc. Jpn. 1995, $68,1168-1171$.

[4] L. Juhász, L. Szilágyi, S. Antus, J. Visy, F. Zsila, M. Simonyi, Tetrahedron 2002, 58, 4261-4265.

[5] L. Kiss, T. Kurtán, S. Antus, A. Bényei, Chirality 2003, $15,558-563$.

[6] T. A. Engler, K. O. LaTessa, R. Iynegar, W. Chai, K. Agrios, Bioorg. Med. Chem. 1996, 4, $1755-1769$.

[7] M. Nagakawa, K. Nakanishi, L. L. Darko, J. A. Vick, Tetrahedron Lett. 1982, 23, 3855-3858.
[8] I. Németh, K. Gulácsi, S. Antus, S. Kéki, M. Zsuga, Nat. Prod. Commun. 2006, 1, $991-996$.

[9] W. G. Dauben, G. J. Fonken, D. S. Noyce, J. Am. Chem. Soc. 1956, 78, 2579-2582.

[10] R. S. Varma, H. Varma, Synth. Commun. 1982, 12, $927-930$

[11] V. V. Zhdankin，P. J. Stang，Chem. Rev. 2008，108, $5299-5358$

[12] Details will be published by A. Mándi et al.

[13] J. W. Clark-Lewis, Austr. J. Chem. 1968, 21, 3015-3024.

[14] R. M. Moriarty, O. Prakash, J. Org. Chem. 1985, 50, $151-153$ 